\title{
Late Brain Oligometastases Diagnosed at Least 36 Months after Cancer Detection are Associated with Favorable Survival Outcome
}

\author{
Carsten Nieder ${ }^{1}$, Bård Mannsåker ${ }^{1}$, Rosalba Yobuta ${ }^{1}$ \\ 1. Oncology, Nordland Hospital Trust, Bodø, NOR
}

Corresponding author: Carsten Nieder, nieder_radonc_tum@hotmail.com

\section{Abstract \\ Objective}

The aim of this study was to investigate the impact of a long disease-free interval (at least 36 months from the first diagnosis of cancer) on survival in patients with brain oligometastases (maximum four lesions, no extracranial metastases).

\section{Methods}

This study involves a retrospective analysis in a group of 89 patients treated with different brain-directed approaches.

\section{Results}

We identified seven patients (8\%) with an interval from cancer diagnosis to the development of brain metastases of at least 36 months. The median time interval was five months. The one-year survival rates were $80 \%$ (interval of at least 36 months) and $43 \%$ (shorter interval), respectively $(p=0.049$ ).

Correspondingly, a large difference in actuarial median survival was observed (39.9 months [95\% confidence interval, 16.8-63.0 months] versus 9.7 months (95\% confidence interval, 6.1-13.3 months). However, the two Kaplan-Meier curves were not statistically significantly different, $p=0.13$. In addition to treatment-related differences, the two groups also differed with regard to the type of primary tumor (high versus low rates of non-small cell lung cancer) and gender.

\section{Conclusion}

Late dissemination was uncommon. The often applied strategy of effective local treatment for patients with brain-only oligometastases is warranted, especially if the disease-free interval had been at least 36 months. Larger studies are needed to fully understand the impact of confounding factors, such as gender and tumor biology.

Received 10/25/2019

Review began 10/29/2019 Review ended 01/01/2020 Published 01/03/2020

() Copyright 2020

Nieder et al. This is an open access article distributed under the terms of the Creative Commons Attribution License CC-BY 3.0., which permits unrestricted use, distribution, and reproduction in any medium, provided the original author and source are credited.
Categories: Radiation Oncology, Neurosurgery, Oncology

Keywords: oligometastases, brain metastases, neurosurgery, long-term survival, radio-surgery

\section{Introduction}

Only a small proportion of patients with brain metastases are diagnosed with brain-only oligometastatic disease [1-3]. Commonly, the development of extracranial metastatic sites precedes the development of brain metastases, or widespread intra- and extracranial metastases are detected simultaneously [4-6]. Paralleling the evolving treatment paradigms for liver and lung oligometastases, management of brain oligometastases has changed, too [7-14]. Increasing utilization of surgical resection and/or stereotactic high-dose radiotherapy has resulted in high rates of local control, which in turn has improved overall survival in patients with true oligometastatic disease [1,13]. The fact that a significant proportion of patients are diagnosed with additional metastases within one year of local ablation illustrates the current challenges of diagnostic imaging (presence of small metastases below the threshold of detection), but also tumor biology and genetics, as comprehensively reviewed in references [15-17]. Recently, evidence for heterogeneous metastatic virulence has been provided [18]. As proposed by the authors, it is not sufficient to stratify solely on the basis of the number of lesions and involved sites. Instead, assessing the pace of dissemination is necessary. In a report by Pastorino et al., five-year overall survival was $45 \%$ for patients with a disease-free interval of at least 36 months [19]. Treatment consisted of lung metastasectomy in more than 5000 cases. In light of this scientific background, we chose to study the pace of dissemination in a different context, i.e. brain oligometastases. We chose the identical cut-off of at least 36 months of diseasefree interval as in reference [19]. We hypothesized that slow dissemination (disease-free interval at least 36 months) would be associated with longer survival also in this patient population. 


\section{Cureus}

\section{Materials And Methods}

\section{Patients and treatment}

We performed a retrospective study of all patients with maximum four parenchymal brain metastases from histologically confirmed extracranial primary tumors treated at our hospital, where we maintain and update a previously utilized database [3,5]. Patients with leptomeningeal metastases or extracranial distant metastases were excluded, resulting in 89 patients with brain-only oligometastases. Their treatment was individualized and consisted of stereotactic radiosurgery (SRS), surgical resection, whole-brain radiotherapy (WBRT), or combinations of different brain-directed approaches. The typical WBRT regimen was 10 fractions of $3 \mathrm{~Gy}$. Systemic treatment was usually prescribed as judged appropriate by the patients' medical oncologists. The patients were treated between January 01, 2007 and December 31, 2018. Brain magnetic resonance imaging (MRI) was performed to assess the number of intracranial metastases and to exclude leptomeningeal disease. Extracranial staging was not standardized and did therefore not always include positron emission tomography (PET) combined with computed tomography (CT).

\section{Statistical methods}

Overall survival (time to death) from the first day of brain-directed therapy was calculated using the KaplanMeier method, and different groups were compared using the log-rank test (SPSS 25, IBM Corp., Armonk, NY, USA). Sixteen patients were censored after a median follow-up of 15 months (range: 2-96 months). The date of death was known in all other patients. Given that the median follow-up was 15 months, we selected the one-year survival rates as the primary endpoint and compared these rates with the two-tailed Fisher's exact probability test (dichotomized by an interval less than 36 versus at least 36 months). Statistical significance was defined as $p<0.05$ throughout this study.

\section{Results}

\section{Patient characteristics}

We identified seven patients (8\%) with interval from cancer diagnosis to development of brain metastases of at least 36 months. In 37 patients (42\%) brain metastases were detected already at first staging, i.e. simultaneous presentation when diagnosed with cancer. Overall, the median time interval was five months. Further patient characteristics are shown in Table 1.

\begin{tabular}{|c|c|c|}
\hline & Short interval <36 months & Interval at least 36 months \\
\hline Median age (years), range & $65,28-90$ & $74,56-83$ \\
\hline Median number of metastases & $1,1-4$ & $1,1-4$ \\
\hline Median KPS & $80,50-100$ & $80,70-90$ \\
\hline Female gender & $38(46 \%)$ & $7(100 \%)$ \\
\hline NSCLC & $51(62 \%)$ & $1(14 \%)$ \\
\hline Breast cancer & $4(5 \%)$ & $2(29 \%)$ \\
\hline Malignant melanoma & $4(5 \%)$ & $2(29 \%)$ \\
\hline Kidney cancer & $4(5 \%)$ & $1(14 \%)$ \\
\hline Colorectal cancer & $6(7 \%)$ & $1(14 \%)$ \\
\hline Others & $13(16 \%)$ & 0 \\
\hline Neurosurgical resection & 32 (39\%) & $5(71 \%)$ \\
\hline Primary WBRT & 31 (38\%) & 0 \\
\hline SRS and other RT & 19 (23\%) & $2(29 \%)$ \\
\hline
\end{tabular}

\section{TABLE 1: Patient characteristics and primary treatment of brain metastases}

KPS: Karnofsky performance status, NSCLC: non-small cell lung cancer, WBRT: whole-brain radiotherapy, SRS: stereotactic radiosurgery, RT: radiotherapy

\section{Survival}


The one-year survival rates were $80 \%$ in patients with a time interval of at least 36 months and $43 \%$ (shorter interval), respectively ( $p=0.049)$. Correspondingly, a large difference in actuarial median survival was observed (39.9 months (95\% confidence interval 16.8-63.0 months) versus 9.7 months (95\% confidence interval 6.1-13.3 months). However, the two Kaplan-Meier curves were not statistically significantly different, $\mathrm{p}=0.13$ (Figure 1).

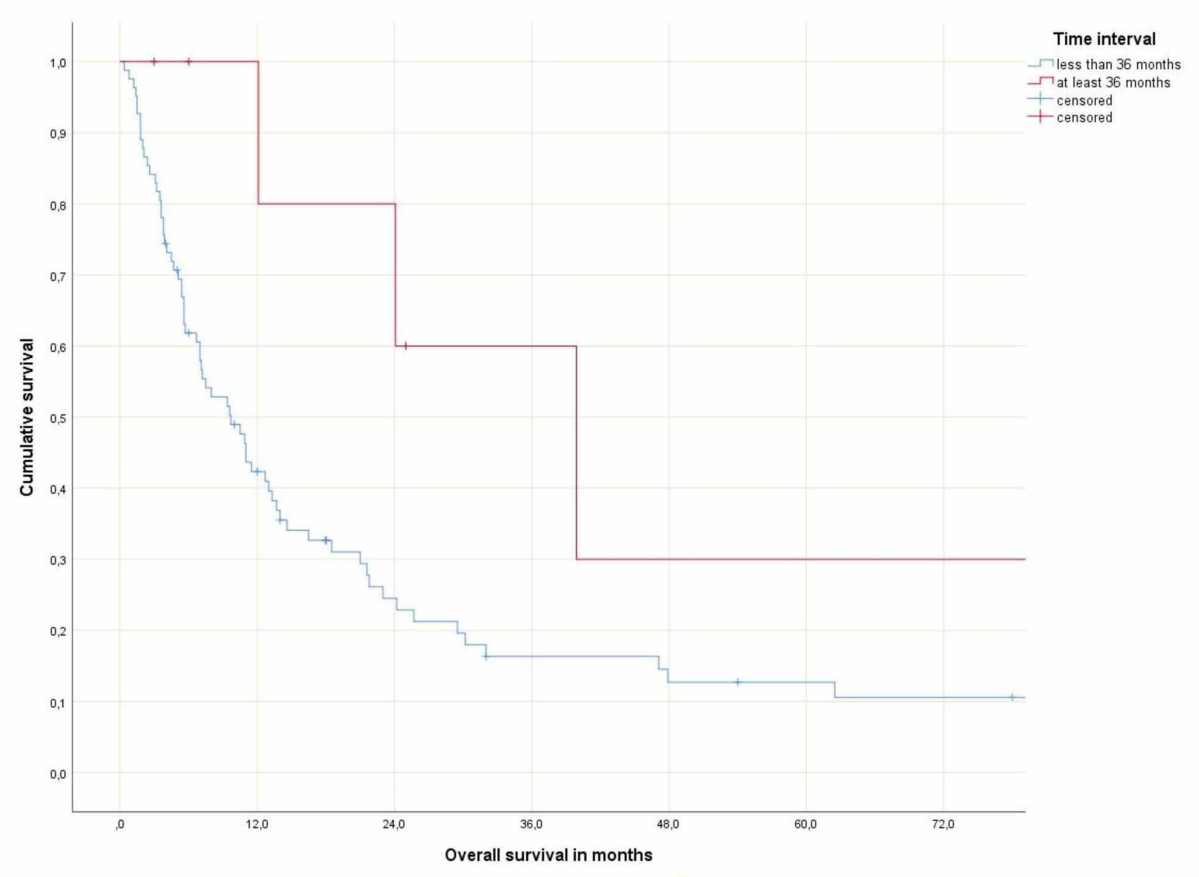

FIGURE 1: Actuarial overall survival

\section{Discussion}

In a large study of lung metastasectomy by Pastorino et al., five-year overall survival was $45 \%$ for patients with a disease-free interval of at least 36 months [19]. In the present study of patients with brain-only oligometastases (less than five), we also found that slow dissemination (disease-free interval at least 36 months) was associated with longer survival. The five-year rate was 30\%. When including censored observations with relatively short follow-up of less than one year, the Kaplan-Meier curves did not show a statistically significant difference, despite large differences in actuarial median survival. Unfortunately, the statistical power of a subgroup analysis that only includes seven patients is very limited. We were surprised to discover that very few patients (8\%) had time intervals of at least 36 months. On the other hand, previous studies have often reported median time intervals of 12 months or less, indirectly confirming that late dissemination is uncommon [20-25].

Based on the different treatment approaches displayed in Table 1, one cannot exclude that high rates of neurosurgical resection $(71 \%)$ have contributed to prolonged survival in patients with long time intervals. It is understandable that histological confirmation of brain dissemination is desirable if no extracranial disease activity can be detected and the previous cancer diagnosis was established several years ago. In addition to treatment-related differences, the two groups also differed with regard to the type of primary tumor (high versus low rates of non-small cell lung cancer) and gender. It is thus difficult to conclude that time interval by itself is the main explanation for the favorable survival outcome of patients treated for brain metastases at least 36 months after their initial cancer diagnosis. Unfortunately, the potential role of the confounding factors mentioned above cannot be addressed in a meaningful way with the statistical power provided by the group sizes in the present study. Our findings should stimulate further research, which may provide reliable explanations for the observed differences in survival. In order to create large databases, multi-institutional and international cooperation should be attempted. Clearly, both tumor biology and treatment have the potential to influence prognosis. Despite the lack of definitive answers, our data suggest that the commonly applied strategy of effective local treatment for patients with brain-only oligometastases is warranted, especially if the disease-free interval has been at least 36 months. Long-term survival has also been observed in patients with simultaneous brain metastases and those with relatively short intervals, as shown in Figure 1.

Most patients in this study had solitary brain metastases. Commonly, the presence of 1-4 metastases triggers a recommendation towards SRS or resection rather than WBRT $[1,4,13]$. Therefore this cut-off was applied in our study. On the other hand, SRS is also feasible in many patients with five or more metastases 
[12]. Optimal patient selection is an area of ongoing research. In parallel, ablative local therapy for extracranial oligometastases continues to evolve and is hoped to contribute to higher rates of long-term survivors [26-30]. Besides suboptimal statistical power and retrospective collection of information, as well as variable staging procedures (some patients with undetected extracranial metastases may have been included), the present study is also limited by the lack of information about the cause of death and development of widespread metastatic disease during follow-up.

\section{Conclusions}

Late dissemination to the brain only was uncommon (8\%). The often applied strategy of effective local treatment for patients with brain-only oligometastases, e.g. SRS or surgery, is warranted, especially if the disease-free interval before the detection of brain metastases has been at least 36 months. Larger studies are needed to confirm statistical significance (log-rank test) and fully understand the impact of confounding factors, such as gender and tumor biology, which may vary greatly with the type of primary tumor.

\section{Additional Information \\ Disclosures}

Human subjects: Consent was obtained by all participants in this study. REK Nord issued approval not applicable. For retrospective quality of care studies such as the present one approval is not required in Norway. Animal subjects: All authors have confirmed that this study did not involve animal subjects or tissue. Conflicts of interest: In compliance with the ICMJE uniform disclosure form, all authors declare the following: Payment/services info: All authors have declared that no financial support was received from any organization for the submitted work. Financial relationships: All authors have declared that they have no financial relationships at present or within the previous three years with any organizations that might have an interest in the submitted work. Other relationships: All authors have declared that there are no other relationships or activities that could appear to have influenced the submitted work.

\section{References}

1. Mazzola R, Corradini S, Gregucci F, Figlia V, Fiorentino A, Alongi F: Role of radiosurgery/stereotactic radiotherapy in oligometastatic disease: Brain oligometastases. Front Oncol. 2019, 9:206. 10.3389/fonc.2019.00206

2. Onesti CE, Iacono D, Angelini S, et al.: Unexpected long survival of brain oligometastatic non-small cell lung cancer (NSCLC) treated with multimodal treatment: a single-center experience and review of the literature. Transl Lung Cancer Res. 2016, 5:712-719. 10.21037/tlcr.2016.09.01

3. Nieder C, Hintz M, Oehlke O, Bilger A, Grosu AL: The TNM 8 M1b and M1c classification for non-small cell lung cancer in a cohort of patients with brain metastases. Clin Transl Oncol. 2017, 19:1141-1146. 10.1007/s12094-017-1651-0

4. Valiente M, Ahluwalia MS, Boire A, et al.: The evolving landscape of brain metastasis . Trends Cancer. 2018, 4:176-196. 10.1016/j.trecan.2018.01.003

5. Nieder C, Haukland E, Mannsåker B, Pawinski AR, Yobuta R, Dalhaug A: Presence of brain metastases at initial diagnosis of cancer: Patient characteristics and outcome. Cureus. 2019, 11:4113. 10.7759/cureus.4113

6. Nieder C, Guckenberger M, Gaspar LE, et al.: Management of patients with brain metastases from non-small cell lung cancer and adverse prognostic features: multi-national radiation treatment recommendations are heterogeneous. Radiat Oncol. 2019, 14:33. 10.1186/s13014-019-1237-9

7. Palma DA, Louie AV, Rodrigues GB: New strategies in stereotactic radiotherapy for oligometastases . Clin Cancer Res. 2015, 21:5198-5204. 10.1158/1078-0432.CCR-15-0822

8. Stenman M, Sinclair G, Paavola P, Wersäll P, Harmenberg U, Lindskog M: Overall survival after stereotactic radiotherapy or surgical metastasectomy in oligometastatic renal cell carcinoma patients treated at two Swedish centres 2005-2014. Radiother Oncol. 2018, 127:501-506. 10.1016/j.radonc.2018.04.028

9. Dohopolski MJ, Horne Z, Clump D, Burton SA, Heron DE: Stereotactic body radiation therapy for pulmonary oligometastases arising from non-lung primaries in patients without extrapulmonary disease. Cureus. 2018, 10:2167. 10.7759/cureus.2167

10. Tomlinson JS, Jarnagin WR, DeMatteo RP, et al.: Actual 10-year survival after resection of colorectal liver metastases defines cure. J Clin Oncol. 2007, 25:4575-4580. 10.1200/JCO.2007.11.0833

11. Ruers T, Van Coevorden F, Punt CJ, et al.: Local treatment of unresectable colorectal liver metastases: results of a randomized phase II trial. J Natl Cancer Inst. 2017, 109:9. 10.1093/jnci/djx015

12. Kraft J, Zindler J, Minniti G, Guckenberger M, Andratschke N: Stereotactic radiosurgery for multiple brain metastases. Curr Treat Options Neurol. 2019, 21:6. 10.1007/s11940-019-0548-3

13. Sittenfeld SMC, Suh JH, Murphy ES, Yu JS, Chao ST: Contemporary management of 1-4 brain metastases . Front Oncol. 2018, 8:385. 10.3389/fonc.2018.00385

14. Andratschke N, Kraft J, Nieder C, Tay R, Califano R, Soffietti R, Guckenberger M: Optimal management of brain metastases in oncogenic-driven non-small cell lung cancer (NSCLC). Lung Cancer. 2019, 129:63-71. 10.1016/j.lungcan.2018.12.009

15. deSouza NM, Liu Y, Chiti A, et al.: Strategies and technical challenges for imaging oligometastatic disease: Recommendations from the European Organisation for Research and Treatment of Cancer imaging group. Eur J Cancer. 2018, 91:153-163. 10.1016/j.ejca.2017.12.012

16. Joice GA, Rowe SP, Pienta KJ, Gorin MA: Oligometastatic prostate cancer: shaping the definition with molecular imaging and an improved understanding of tumor biology. Curr Opin Urol. 2017, 27:533-541. 10.1097/MOU.0000000000000449

17. Pitroda SP, Khodarev NN, Huang L, et al.: Integrated molecular subtyping defines a curable oligometastatic 
state in colorectal liver metastasis. Nat Commun. 2018, 9:1793. doi: 10.1038/s41467-018-04278-6.

18. Foster CC, Pitroda SP, Weichselbaum RR: Staging the metastatic spectrum through integration of clinical and molecular features. J Clin Oncol. 2019, 37:1270-1276. 10.1200/JCO.18.02021

19. Pastorino U, Buyse M, Friedel G, et al.: Long-term results of lung metastasectomy: prognostic analyses based on 5206 cases. J Thorac Cardiovasc Surg. 1997, 113:37-49.

20. Shibahara I, Kanamori M, Watanabe T, et al.: Clinical features of precocious, synchronous, and metachronous brain metastases and the role of tumor resection. World Neurosurg. 2018, 113:1. 10.1016/i.wneu.2017.10.145

21. Kim HJ, Im SA, Keam B, et al.: Clinical outcome of central nervous system metastases from breast cancer: differences in survival depending on systemic treatment. J Neurooncol. 2012, 106:303-313. 10.1007/s11060011-0664-8

22. Baek JY, Kang MH, Hong YS, et al.: Characteristics and prognosis of patients with colorectal cancerassociated brain metastases in the era of modern systemic chemotherapy. J Neurooncol. 2011, 104:745-753. 10.1007/s11060-011-0539-z

23. Rades D, Haatanen T, Schild SE, Dunst J: Dose escalation beyond 30 grays in 10 fractions for patients with multiple brain metastases. Cancer. 2007, 110:1345-1350. 10.1002/cncr.22906

24. Nieder C, Andratschke NH, Geinitz H, Grosu AL: Diagnosis-specific graded prognostic assessment score is valid in patients with brain metastases treated in routine clinical practice in two European countries. Med Sci Monit. 2012, 18:450-455. 10.12659/MSM.883213

25. Nieder C, Bremnes RM, Andratschke NH: Prognostic scores in patients with brain metastases from nonsmall cell lung cancer. J Thorac Oncol. 2009, 4:1337-1341. 10.1097/JTO.0b013e3181b6b6f4

26. Wong AC, Watson SP, Pitroda SP, et al.: Clinical and molecular markers of long-term survival after oligometastasis-directed stereotactic body radiotherapy (SBRT). Cancer. 2016, 122:2242-2250. 10.1002/cncr.30058

27. Ashworth AB, Senan S, Palma DA, et al.: An individual patient data metaanalysis of outcomes and prognostic factors after treatment of oligometastatic non-small-cell lung cancer. Clin Lung Cancer. 2014, 15:346-355. 10.1016/j.cllc.2014.04.003

28. Haidenberger A, Heidorn SC, Kremer N, Muacevic A, Fürweger C: Robotic radiosurgery for adrenal gland metastases. Cureus. 2017, 9:1120. 10.7759/cureus.1120

29. Gomez DR, Blumenschein GR Jr, Lee JJ, et al.: Local consolidative therapy versus maintenance therapy or observation for patients with oligometastatic non-small-cell lung cancer without progression after first-line systemic therapy: a multicentre, randomised, controlled, phase 2 study. Lancet Oncol. 2016, 17:1672-1682. 10.1016/S1470-2045(16)30532-0

30. Trovo M, Furlan C, Polesel J, et al.: Radical radiation therapy for oligometastatic breast cancer: Results of a prospective phase II trial. Radiother Oncol. 2018, 126:177-180. 10.1016/j.radonc.2017.08.032 